Advanced Graphics on VGA and XGA Cards Using Borland $\mathrm{C}++$ 


\title{
Advanced Graphics on VGA and XGA Cards Using Borland $\mathrm{C}++$
}

\author{
Ian O. Angell and \\ Dimitrios Tsoubelis \\ Department of Information Systems \\ London School of Economics
}

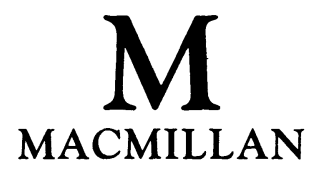


All rights reserved. No reproduction, copy or transmission of this publication may be made without written permission.

No paragraph of this publication may be reproduced, copied or transmitted save with written permission or in accordance with the provisions of the Copyright, Designs and Patents Act 1988, or under the terms of any licence permitting limited copying issued by the Copyright Licensing Agency, 90 Tottenham Court Road, London W1P 9HE.

Any person who does any unauthorised act in relation to this publication may be liable to criminal prosecution and civil claims for damages.

First published 1992 by

THE MACMILLAN PRESS LTD

Houndmills, Basingstoke, Hampshire RG21 2XS

and London

Companies and representatives

throughout the world

ISBN 978-1-349-22338-1

ISBN 978-1-349-22336-7 (eBook)

DOI 10.1007/978-1-349-22336-7

A 3.5 in. MS-DOS disk containing all the program listings, plus VGA communication with the XGA driver, and other utilities, is available at the price of $£ 25.00$ or $\$ 40.00$ (inc. postage/packing - airmail overseas).

Please send your personal cheque to: Globe Book Services Ltd, Houndmills, Basingstoke, Hampshire, RG21 2XS, UK.

Access/Visa/American Express/Diners Club accepted. Please quote number and expiry date.

Please quote ISBN 978-0-333-56766-1 (disk) when ordering.

A catalogue record for this book is available from the British Library.

Borland $\mathrm{C}++$ is a trademark of Borland International Inc. IBM and PS $/ 2$ are trademarks of International Business Machines Corporation.

HP-GL/2 is Hewlett-Packard's graphics language for printers. 
dedicated to

Florence and $A \gamma \gamma \varepsilon \lambda \iota \kappa \eta$ 


\section{Contents}

$\begin{array}{ll}\text { Preface } & \text { viii }\end{array}$

1 Familiarization with graphics adapters and $\mathrm{C}_{++}$programs 1

2 A window on two-dimensional space 29

3 Data structures 47

4 An introduction to two-dimensional co-ordinate geometry 71

5 Points, lines and polygonal facets $\quad 86$

6 Three-dimensional co-ordinate geometry 104

7 Matrix transformations for modelling 3-D space 127

8 The observer. Orthographic and perspective projections. Clipping 160

9 Generation of model data 193

10 Hidden surface algorithms 214

11 Shading 236

12 Shadows, transparent surfaces and reflections 268

13 The analytic approach 287

14 A quad-tree algorithm 294

15 An oct-tree algorithm 303

16 Ray-tracing $\quad 321$

$\begin{array}{ll}\text { Appendix } & 335\end{array}$

Bibliography $\quad 360$

Index $\quad 363$

Index of functions and methods $\quad 378$ 


\section{Preface}

This book will enable you to produce top quality three-dimensional computer graphics images, using only a VGA or XGA graphics adapter; images of a quality that would normally need very expensive computer graphics terminals and software. Now, in this book you will find all the program listings required to create highly sophisticated three-dimensional graphics. Apart from the cards all you need buy is a copy of the Borland $\mathrm{C}_{++}$compiler, and this book of course!

There are many excellent books available on computer graphics; however, very few give actual program listings, and even those that do are aimed at expensive installations. We give listings that run on IBM PS/2 compatible machines, and include the polygonal mesh, quad-tree, oct-tree and ray-tracing display methods. We cover such topics as modelling and transformation of objects, hidden surface removal, smooth shading, shadows, transparency and reflections. A full explanation of all these concepts, including the underlying mathematics and data structures, is given alongside the listings.

With this book, advanced computer graphics is no longer restricted to a few well-funded institutions and research groups. The real benefit is that any college, polytechnic or university, that probably already own microcomputers with standard VGA (or with the more advanced XGA) screens can now offer an advanced practical course in computer graphics without incurring any further expenditure; they no longer need costly graphics terminals.

This book is the culmination of fifteen years experience of research in computer graphics and of teaching the subject at undergraduate and postgraduate level at three colleges of the University of London. The text contains all of the program listings for the course; the Borland $\mathrm{C}++$ programming environment was chosen because of its growing popularity and ease of use. The Borland Project mechanism is a highly effective means of bringing together all the listings in the book and building it into a comprehensive graphics package. (See chapter 2 for a full description of structure of programs using the Project mechanism.) This package is intended to be the basis from which students can experiment in advanced graphics. All the listings in the book are available on a 3.5 inch flexible disk. No copyright restrictions are placed on academic use of the programs, although the permission of the authors is needed for any commercial application. 
Prior to this book, one of the authors, Ian Angell has published four highly successful books (using Pascal and C, and two using Fortran) based on his very practical approach to teaching computer graphics. Universities and polytechnics from all around the world have based their courses on the text and programs in these earlier books. Researchers too, in subjects as diverse as archaeology, architecture, agriculture, chemistry, geography, geology, marine biology and physics, to name but a few, have found the programs invaluable in their work.

For the present book, Ian Angell has been joined by Dimitrios Tsoubelis and together they have produced a major rewrite of the course. All the programs were completely redesigned to make the fullest use of the object oriented nature of C+t. A totally new section (theory and listings) on analytic methods has been added. All of the colour plates and most of the line drawings are new; to be true to their pedagogical approach, all the three-dimensional images have been drawn using the programs given in this book, using the VGA and XGA cards, and not on more sophisticated (and expensive) graphics equipment.

The course starts with an introduction to the VGA (or XGA) graphics cards. Then, using some small, yet quite sophisticated graphics programs, we show how to 'drive' either card from within $\mathrm{C}_{++}$programs running on IBM PS/2 compatible machines to draw pictures. We then introduce the idea of a window in continuous two-dimensional space, which is designed so that points, lines or areas defined in the window can be drawn on the screen; again some very interesting images illustrate these ideas.

Then we start in earnest. Data structures necessary for graphics are described in the third chapter, and useful concepts from two-dimensional co-ordinate geometry are introducd in chapter 4 . Then follows a discussion of manipulating points, lines and polygonal facets in the window. But before we can draw 'solid' objects, in chapter 6 we introduce three-dimensional co-ordinate geometry. Then we can introduce a database for descriptions of three-dimensional scenes, and explain how matrices are used to transform those scenes (chapter 7). Here we introduce the polygonal-mesh approach in which we approximate to the surfaces of objects in a three-dimensional scene with a mesh of polygonal facets. Then the idea of an observer is introduced, so that we can project three-dimensional space onto a two-dimensional window, from which we can draw the scene on the graphics screen. In chapter 9 we consider how to generate complex models.

In chapter 10 we show how parts of the surfaces of objects, obscured from view by the bulk of objects in the scene (so-called hidden surfaces), can be eliminated from the drawing. In chapter 11 we make these pictures look more realistic by introducing a light source, and by shading the surfaces of objects. Then in chapter 12 we consider shadows, transparency and reflection. 
At that stage we have come close to the limits of the polygonal mesh approach, and in the last four chapters we introduce a totally different way of modelling objects: the analytic approach. From the basis of this new type of mathematical modelling, we give three ways of drawing such objects: with a quad-tree algorithm, an oct-tree algorithm, and we finish with ray-tracing.

$\mathrm{C}++$ is a joy to use when writing graphics programs. By its very nature it gives the programmer a great variety of predefined data types, but what is more important it gives the freedom to create new data types that can be manipulated with the same efficiency as the standard ones. Another important feature of all object oriented languages is the ability to partition a huge application program into smaller, more manageable chunks. This lets the programmer break projects into a set of distinct concepts, and to program each of them separately. This is a very efficient way of implementing large projects, since each logical concept can be programmed and tested independently. Additionally, processes common to more than one logical concept need be programmed once only, and reused. This programming approach, emphasising the reduction of the initial problem into sub-problems, lends itself directly to the theoretical way we organized this graphics course, so the book consists of building up files (see chapter 2).

It comes as no surprise therefore that the literature on object oriented programming contains so many examples from computer graphics applications. However, we do not adopt the very common practice of choosing the point on the screen (the pixel) or the point in space as the basic object (class) out of which everyting else inherits. We place our emphasis on the great variety of complex processes involved in a typical computer graphics application, rather than on the set of pixels composing the final image. Our primary focus is on the analysis and understanding of the algorithms used in computer graphics. As a result, our design approach will split a typical computer graphics application in entities (classes) like the Viewport, the Palette, the graphics Window, the object database Cluster, and so on. Moreover, a toolbox of useful data structures like Matrix, Stack, Mesh and Tree are also defined and used extensively. Another advantage of our approach is that it has been designed to cope with the segmentation of the DOS system, even when dealing with large data sets.

So read on. We hope that you find our programs, examples, exercises and projects interesting and useful, and that they inspire you to go on to experiment with computer graphics and to discover much more about this enjoyable subject. For computer graphics really is fun. So take this book straight back to your microcomputer and start enjoying yourself! 